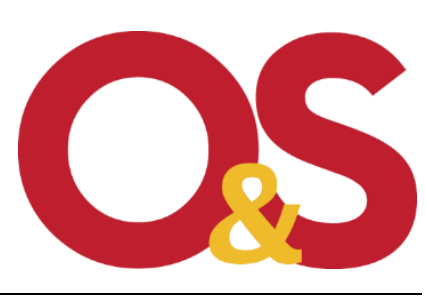

Revista Organizações \& Sociedade 2021, 28(96), 1-8

(C) Autores 2021

DOI 10.1590/1984-92302021v28n9600PT

\title{
Editorial
}

ISSN 1984-9230

www.revistaoes.ufba.br

NPGA, Escola de Administração

Universidade Federal da Bahia

\section{Impacto Simbólico da Pesquisa}

\author{
Josiane Silva de Oliveira ${ }^{a}$ \\ Eduardo Paes Barreto Davel ${ }^{\text {b }}$ \\ a Universidade Estadual de Maringá, Maringá, Brasil \\ b Universidade Federal da Bahia, Salvador, Brasil
}

\section{Resumo}

Muito se discute sobre o impacto da pesquisa científica para a sociedade, e os entendimentos se concentram nas dimensões econômicas, sociais, culturais e tecnológicas. Carecemos de um melhor entendimento sobre esse impacto em suas dimensões culturais e, em específico, sobre suas dimensões simbólicas. Todo resultado de pesquisa carrega em si uma carga simbólica que impacta organizações e sociedade. Então, pesquisadores precisam pensar a forma de construírem os resultados de suas pesquisas a partir de uma consciência e sensibilidade a esse possível impacto simbólico. Os impactos simbólicos são determinantes para apreendermos o valor sutil, profundo e estruturante que os resultados de pesquisa podem acarretar para o desenvolvimento e transformação da sociedade e das organizações.

Palavras-chave: impacto; pesquisa; simbolismo.

\section{Introdução}

O debate sobre o impacto da pesquisa científica na sociedade encontra-se no centro das atenções contemporâneas. Frequentemente, as dimensões destacadas desse impacto são as dimensões econômica, social, governamental, organizacional, tecnológica, cultural e educacional. A dimensão cultural do impacto da pesquisa é reduzida ao estímulo e enriquecimento da produção cultural e à preservação da herança cultural das nações (Bornmann, 2012; Brook, 2018). Portanto, carecemos de um melhor entendimento sobre o impacto em suas dimensões culturais e, em 
específico, sobre suas dimensões simbólicas. O simbolismo é fundamental para nos compreendermos como sociedade (Bourdieu, 1989; Cassirer, 2001, 2004, 2011; Cohen, 1985; Eliade, 1980; Goldschmidt, 1990; Hamlin \& Krois, 2004; Jung, 1968; Scheffler, 1997); então, por que não pensamos e consideramos plenamente o impacto da pesquisa no âmbito simbólico?

Discutir impactos de pesquisas científicas, acaba se restringindo, muitas vezes, ao entendimento sobre a necessidade de mensurar seus efeitos. O resultado é que relações causais ou formas de escalonamento tornam-se as estratégias mais utilizadas na realização desse debate (Sandes-Guimarães \& Hourneaux, 2020). No entanto, existem impactos que são predominantemente subjetivos e que, apesar de não mensuráveis, quando compreendidos, possibilitam apreender de forma muito evidente como as produções e publicações científicas impactam profundamente nossas práticas culturais e sustentam a criação de sentido do que é viver em sociedade. Afinal, a forma como a ciência se desenvolve - no sentido de identificar problemas, discutir e apresentar respostas à sociedade - tem relação direta com a forma como a sociedade se relaciona com a ciência, do ponto de vista simbólico.

Quem produz o conhecimento científico, como produz e o que produz também deve ser considerado nesse processo. Nossas práticas científicas, que também são práticas simbólicoculturais, são formas de ser (e de se representar) da sociedade e das organizações. Então, além de pensarmos problemas, práticas e resultados que produzam impactos dos pontos de vista econômico, financeiro e social, é preciso que nós reflitamos sobre os impactos simbólicos que essas produções podem produzir. Os resultados de uma pesquisa podem alterar significativamente as percepções em relação ao campo científico e a seus objetos de estudos.

Ao considerarmos que nossas práticas científicas também são práticas culturais (Pickering, 1992; Taylor, 1994), percebemos que a sociedade pode e deve se identificar com a ciência que é produzida. Isso não significa a reprodução do senso comum em nossas atividades, tampouco a apresentação de respostas que estabilizem nossas relações sociais. Nossa produção científica deve acontecer no sentido de gerar símbolos e representação simbólica que provoque a sociedade a refletir, questionar e romper com determinadas representações, conhecimentos e visões de mundo opressoras. Ou seja, todo resultado de pesquisa carrega em si uma carga simbólica que acarreta impacto simbólico nas organizações e na sociedade. Então, pesquisadores precisam pensar a forma de construírem os resultados de suas pesquisas a partir de uma consciência e sensibilidade a esse possível impacto simbólico.

A produção científica pode e deve ser pensada a partir de seu impacto simbólico (Haro, 2017; Koch \& Vanderstraeten, 2018; Minayo, Gomes, \& Silva, 2020; Vessuri, Guédon, \& Cetto, 2014). Neste editorial, buscamos destacar a importância de pensar o impacto da pesquisa científica no âmbito do simbólico, tanto para a sociedade quanto para as organizações. Dessa forma, pretendemos ampliar e aprofundar a reflexão sobre os impactos da pesquisa e suas aplicações nas instituições regulatórias da ciência.

\section{Dimensão simbólica das organizações e sociedade}

O simbolismo foi alvo de muitas investigações realizadas pela antropologia, pelas ciências sociais e pelos estudos organizacionais, ao entender que sociedades e organizações são constituídas por símbolos. O simbolismo refere-se aos processos intersubjetivos que substanciam os modos 
como as pessoas produzem, apreendem e interpretam o contexto no qual estão inseridas para a constituição de suas práticas (Geertz, 1978). Como tal, não se trata somente da dimensão abstrata da vida concreta, mas como a realidade pode fazer sentido para os indivíduos e se tornar, de fato, algo concreto. A produção simbólica é a produção de sentidos estruturantes e profundos sobre o mundo que fazemos parte e sobre o qual temos, portanto, capacidade de agência, em alguma medida.

Nesse sentido, a dimensão simbólica da sociedade e das organizações nas produções científicas destacam, consciente ou inconscientemente, como estas são sistematizadas a partir do ponto de vista analítico das ciências. Quando produzimos uma pesquisa, as imagens, sentidos e significados que mobilizamos para sistematizar nossas reflexões e resultados científicos evidenciam os processos intersubjetivos que são utilizados a partir de nossa capacidade de agência dessa realidade. Se essa mobilização opera no sentido de reforçar estereótipos, por exemplo, o simbolismo imbricado nessa produção pode fomentar o que Collins (2016) denominou de imagens de controle sobre determinados grupos sociais. Essas imagens visam reproduzir uma lógica de organização social que é constituída a partir de relações de poder que se caracterizam por articulações de dominação e de subordinação. São nossas práticas culturais, marcadas estruturalmente por relações de poder, que substanciam a construção dessa dimensão simbólica da sociedade e das organizações em nossa produção científica. Por isso, torna-se tão necessário refletirmos sobre os impactos simbólicos oriundos dos resultados de nossas pesquisas.

Nos estudos organizacionais, o simbolismo é pensado como fundamento da dinâmica organizacional (Boje, 2002; Carrieri \& Saraiva, 2007; Pondy, Frost, Morgan, \& Danbridge, 1983; Turner, 1990, 1992); como perspectiva de teorização (Hatch \& Cunliffe, 2006); como linguagem de suas relações (Pratt \& Rafaeli, 2001); como fonte de criação de valor (Ravasi \& Rindova, 2008); como ação de gestão (Pfeffer, 1981). Ou seja, o resultado de pesquisas pode afetar simbolicamente organizações em sua dinâmica de funcionamento, nas relações de trabalho, nos processos de criação de valor e na ação de seus gestores. Por exemplo, o estudo de Alcadipani (2014) destaca como os impactos simbólicos de realização de uma etnografia são mediados pelas relações intersubjetivas com os participantes do estudo. O pesquisador relata que mesmo com autorização formal para a realização do trabalho de campo, o receio dos impactos simbólicos no funcionamento do cotidiano laboral pode impedir a realização do estudo. Alcadipani (2014) discute que, em uma organização da área de comunicação no Brasil, o impedimento ocorreu no sentido de que as relações sociais da área operacional fossem identificadas, decodificadas e utilizadas contra esse grupo pela gestão da empresa. No caso de uma organização da área de segurança pública, o receio ocorreu pelo fato da impossibilidade de controle sobre os impactos do estudo, também, na imagem da organização. Ou seja, há uma preocupação sobre como sociedade e organizações serão simbolizadas e representadas nas publicações. Essa preocupação refere-se aos impactos simbólicos que isso pode ter sobre elas.

Por outro lado, também há preocupações sobre como a sociedade é representada no campo científico e não somente como objeto de estudo. A tese de Cardoso (2014) provoca esse debate ao analisar quando as populações não brancas deixam de ser objeto de pesquisa e passam a ocupar o espaço de protagonista desses estudos. Essa alteração de posicionamento não se reflete somente nos resultados das análises, mas em como a sociedade se percebe enquanto coletividade que ocupa diferentes espaços sociais. No estudo de Cardoso (2014), as pessoas brancas que comumente 
colocam os processos de racializações de não brancos como objeto de estudo tiveram que ocupar o lugar que sempre demandaram aos "outros". Isso estimulou um processo simbólico de reflexão sobre quem somos em termos estruturais de campo científico e sociedade. São nessas intersubjetividades que a pesquisa também impacta, simbolicamente, ao evidenciar a concretude da realidade, pois destaca quem somos enquanto campo científico, sociedade e organizações.

A dimensão simbólica não se restringe à contextualização dos resultados da pesquisa a partir da realidade analisada. Ela inclui a apreensão das instabilidades, indagações e questionamentos que temos em relação a quem somos enquanto sociedade e organizações. Portanto, quando falamos em simbolismo, destacamos a relevância de se compreender os impactos intersubjetivos da pesquisa acadêmica, evidenciando essas instabilidades que, por sua vez, evidenciam relações de poder, dominação e subordinação. Quando realizamos uma pesquisa, seu impacto afeta diretamente essas instabilidades. Então, além dos impactos tecnológicos, sociais e econômicos, o impacto simbólico deve ser considerado como uma das dimensões da pesquisa, pois os efeitos no cotidiano organizacional e social serão profundamente evidenciados ou mesmo potencialmente transformados com os resultados de nossas análises.

\section{Impacto simbólico da pesquisa acadêmica}

A mobilização de símbolos, sentidos e significados também faz parte da pesquisa acadêmica. Esse processo não se refere somente à produção de material empírico para a realização de uma pesquisa, mas deve destacar nossa capacidade de mobilizar intersubjetividades no cotidiano de nossas atividades. Isso somente é possível se compreendermos a pesquisa acadêmica no contexto de dinâmicas sociais. $O$ impacto simbólico da pesquisa acadêmica refere-se, portanto, a essa capacidade de mobilização intersubjetiva na pesquisa, na qual as pessoas podem reconhecer o fazer científico e se reconhecer como pertencentes a ele. Nesse sentido, para compreender esse impacto, algumas dimensões podem ser avaliadas na realização do estudo. A primeira delas é a linguagem. $O$ tipo de linguagem utilizada por quem realiza a pesquisa e pelo campo podem ser diferentes. Na medida em que as intersubjetividades são construídas, as linguagens tendem a ser articuladas.

Outro elemento que nos ajuda a avaliar os impactos simbólicos é a dimensão material da pesquisa-que pode ser o corpo humano ou mesmo um objeto. Novamente, a construção intersubjetiva com o campo pode alterar a forma como nos relacionamos conosco e com o ambiente no qual vivemos. Nosso corpo também pode mudar quando realizamos pesquisa de campo (Almeida \& Flores-Pereira, 2013). Da forma de andar ao consumo, das práticas religiosas ao "time do coração", são nossos valores e referências que são colocados em questionamento quando realizamos uma pesquisa. Isso se dá tanto em relação a quem realiza o estudo, quanto aos participantes deste. Não refletir sobre esses elementos profundamente simbólicos é silenciar o "pulsar" do cotidiano da pesquisa, que dá sentido, simbologia e significado ao nosso trabalho como pesquisadoras e pesquisadores. Quantas vezes paramos para pensar o que ficou da pesquisa no campo? O que mudou após nossa passagem por aquela organização? Discutir os impactos simbólicos da pesquisa acadêmica também é pensar processualmente nossa atividade, refletindo, inclusive, sobre as consequências que ficam depois que a gente "se vai".

Por exemplo, no contexto de pandemia no Brasil, o caso da produção da vacina Coronavac pelo Instituto Butantan. Para além do slogan "A vacina do Brasil”, a divulgação, circulação e 
construção simbólica dessa publicação científica foi realizada a partir da estética, linguagem e recursos imagéticos do funk, um gênero musical que, ainda hoje, é alvo de muito preconceito, não somente no campo científico, mas por grande parte da sociedade brasileira (Cymrot, 2011). 0 simbolismo de um jovem da periferia urbana brasileira, MC Fioti, de jaleco branco, produzindo ciência em conjunto com um dos principais institutos de pesquisas do mundo, evidencia um deslocamento de sentidos sobre quem faz ciência e sobre as relações que devem ser tecidas para que essa publicação "vá além do artigo".

É preciso que a sociedade, como um todo, apreenda sua condição nas pesquisas desenvolvidas. Isso requer que essa apreensão represente todas as contradições, controvérsias e conflitos que constitui a sociedade. Desse modo, os impactos simbólicos das publicações científicas podem ser observados nas alterações que acontecem quando estas são realizadas com e para outros e outras que não somente aqueles e aquelas que, historicamente, são considerados e consideradas pertencentes desse campo, assim como em relação aos mecanismos para que isso aconteça. Por exemplo, uma mulher publicando sobre programação computacional, uma pessoa negra sobre temas que não tem as relações raciais como centralidade, uma mulher trans discutindo temas para além da sexualidade, ilustram como as publicações científicas também podem ter um impacto simbólico de rompimento com estereótipos que o próprio campo científico produziu e/ou reproduz. Outro exemplo seria o ato de publicar e/ou divulgar os resultados de uma pesquisa científica em um canal especializado em funk, samba ou pagode e como isso pode evidenciar os impactos simbólicos das publicações científicas.

Em um contexto no qual a validade da ciência tem sido questionada - inclusive por dirigentes de países, a partir de pressupostos, no mínimo, questionáveis -, discutir os impactos simbólicos das publicações científicas coloca-nos o desafio de compreender como fazer com que os resultados de nossas pesquisas não terminem com a publicação do "artigo", mas que, de fato, constituam uma publicação científica, no sentido de produzir conhecimento que seja acessível a toda sociedade e acessado por esta. É preciso reconhecer que a prática científica também é uma prática simbólica e, como tal, deve fazer parte do cotidiano de nossa sociedade, pois as relações intersubjetivas não falam somente da dimensão abstrata, mas da apreensão de nossa realidade concreta; assim como simbolismo não fala somente de abstração, mas de produção sociocultural.

\section{Referências}

Alcadipani, R. (2014). Confissões etnográficas: Fracassos no acesso a organizações no Brasil. Revista Brasileira de Estudos Organizacionais, 1(1), 64-87. doi:10.21583/24474851.rbeo.2014.v1n1.31

Almeida, D. D., \& Flores-Pereira, M. T. (2013). As corporalidades do trabalho bailarino: Entre a exigência extrema e o dançar com a alma. Revista de Administração Contemporânea, 17(6), 720-738. doi:10.1590/S1415-65552013000600006

Boje, D. M. (2002). Organizational symbolism. In A. Sorge (Ed.), Organization (pp. 358-367). London: Thompson Learning. 
Bornmann, L. (2012). What is societal impact of research and how can it be assessed? A literature survey. Journal of the American Society for Information Science and Technology, 64(2), 217233. doi:10.1002/asi.22803

Bourdieu, P. (1989). O poder simbólico. Rio de Janeiro, RJ: Bertrand Brasil.

Brook, L. (2018). Evidencing impact from art research: analysis of impact case studies from the REF 2014. The Journal of Arts Management, Law, and Society, 48(1), 57-69. doi:10.1080/10632921.2017.1386148

Cardoso, L. C. (2014). A branquitude acrítica revisitada e a branquidade. Revista da Associação Brasileira de Pesquisadores(as) Negros(as), 6(13), 88-106.

Carrieri, A. P., \& Saraiva, L. A. (Eds.). (2007). Simbolismo organizacional no Brasil. São Paulo, SP: Atlas.

Cassirer, E. (2001). A filosofia das formas simbólicas: A linguagem. São Paulo, SP: Martins Fontes.

Cassirer, E. (2004). A filosofia das formas simbólicas: O pensamento mítico. São Paulo, SP: Martins Fontes.

Cassirer, E. (2011). A filosofia das formas simbólicas: Vol. 2: Fenomenologia do conhecimento. São Paulo, SP: Martins Fontes.

Cohen, A. P. (1985). The symbolic construction of community. London: Routledge.

Collins, P. H. (2016). Aprendendo com a outsider within: a significação sociológica do pensamento feminista negro. Sociedade e Estado, 31(1), 99-127. doi:10.1590/S0102-69922016000100006

Cymrot, D. (2011). A criminalização do funk sob a perspectiva da teoria crítica (Dissertação de Mestrado). Universidade de São Paulo, São Paulo, SP.

Eliade, M. (1980). Images et symboles: Essais sur le symbolisme magico-religieux. Paris: Gallimard.

Geertz, C. (1978). A interpretação das culturas. Rio de Janeiro, RJ: Zahar.

Goldschmidt, W. (1990). The human career: The self in the symbolic world. Cambridge: Blackwell.

Hamlin, C., \& Krois, J. M. (Eds.). (2004). Symbolic forms and cultural studies: Ernst Cassirer's theory of culture. New Haven: Yale University Press.

Haro, F. A. (2017). O impacto de (não) ter impacto: Para uma sociologia crítica das publicações científicas. Revista Crítica de Ciências Sociais, 113, 83-106. doi:10.4000/rccs.6659

Hatch, M. J., \& Cunliffe, A. L. (2006). Organization theory: Modern, symbolic and postmodern perspectives. Oxford: Oxford University Press.

Jung, C. G. (1968). Man and his symbols. New York: Dell Publishing.

Koch, T., \& Vanderstraeten, R. (2019) Internationalizing a national scientific community? Changes in publication and citation practices in Chile, 1976-2015. Current Sociology, 67(5), 723-741. doi:10.1177/0011392118807514

Minayo, M. C. S., Gomes, R., \& Silva, A. A. M. (2020). 25 anos de ciência para construção do SUS. Ciência \& Saúde Coletiva, 25(3), 780. doi:10.1590/1413-81232020253.34952019 
Pfeffer, J. (1981). Management as symbolic action: The creation and maintenance of organizational paradigms. Research in Organizational Behavior, 3, 1-52.

Pickering, A. (Ed.) (1992). Science as practice and culture. Chicago: University of Chicago Press.

Pondy, L. R., Frost, P. J., Morgan, G., \& Dandridge, T. C. (Eds.). (1983). Organizational symbolism. Greenwich: Jai Press.

Pratt, M. G., \& Rafaeli, A. (2001). Symbols as a language of organizational relationships. Research in Organizational Behavior, 23, 93-132. doi:10.1016/S0191-3085(01)23004-4

Ravasi, D., \& Rindova, V. (2008). Symbolic value creation. In D. Barry \& H. Hensen (Eds.), The SAGE Handbook of New Aproaches in Management and Organizations. Thousand Oaks: Sage.

Sandes-Guimarães, L.V. D., \& Hourneaux Junior, F. (2020). Research impact - what is it, after all? Editorial impact series part 1. RAUSP Management Journal, 55(3), 283-287. doi:10.1108/rausp-07-2020-202

Scheffler, I. (1997). Symbolic worlds: art, science, language, ritual. Cambridge: Cambridge University Press.

Taylor, C. A. (1994). Science as cultural practice: A rhetorical perspective. Technical Communication Quarterly, 3(1), 67-81. doi:10.1080/10572259409364558

Turner, B. R. (Ed.) (1990). Organizational symbolism. Berlin: De Gruyter.

Turner, B. R. (1992). The symbolic understanding of organizations. In M. Reed \& M. Hughes (Eds.), Rethinking organization. Thousand Oaks: Sage.

Vessuri, H., Guédon, J. C., \& Cetto, A. M. (2014). Excellence or quality? Impact of the current competition regime on science and scientific publishing in Latin America and its implications for development. Current Sociology, 62(5), 647-665. doi:10.1177/0011392113512839

\section{Autoria}

\section{Josiane Silva de Oliveira}

Doutora em administração pela Universidade Federal do Rio Grande do Sul. Professora do departamento de administração da Universidade Estadual de Maringá e do Programa de PósGraduação em Administração da Universidade Federal de Goiás. Editora associada da revista Organizações \& Sociedade, eixo "Organizações, teoria e método". Pesquisa e publica na área de estudos baseados em práticas, feminismo negro, etnografia, cultura e artes nos estudos organizacionais.

E-mail: oliveira.josianesilva@gmail.com

ORCID: https://orcid.org/0000-0002-7085-8921

\section{Eduardo Paes Barreto Davel}

Doutor em administração pela École des Hautes Études Commerciales de Montréal (Canadá), com pós-doutorado em administração pela Nova School of Business and Economics da Universidade 
Nova de Lisboa (Portugal). Professor na Escola de Administração da Universidade Federal da Bahia. Editor-chefe da revista Organizações \& Sociedade. Pesquisa e publica sobre empreendedorismo cultural, gestão do processo criativo, ensino, metodologia, aprendizagem, cultura e estética nas organizações.

E-mail: davel.eduardo@gmail.com

ORCID: https://orcid.org/ 0000-0003-0610-6474

\section{Contribuição dos autores}

Primeira autora: concepção (igual), investigação (igual), redação - rascunho original (igual).

Segundo autor: concepção (igual), investigação (igual), redação - rascunho original (igual).

A O\&S é signatária do DORA (The Declaration on Research Assessment) e do COPE (Committee on Publication Ethics).

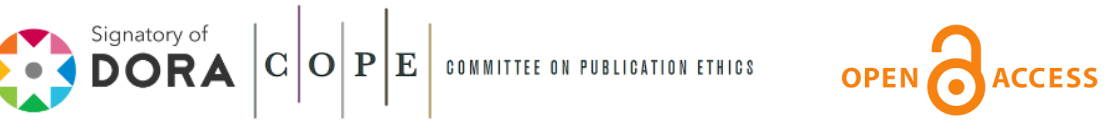

